\title{
Working with probation services and mentally disordered offenders
}

\author{
Rebekah Bourne, Rachna Rajput \& Richard Field
}

\begin{abstract}
SUMMARY
A significant proportion of individuals in contact with probation services have mental health problems. Joint working between psychiatrists and probation is crucial to both diversion and resettlement of offenders with mental health conditions. In England and Wales, probation services are involved in the supervision and management of offenders if they receive a suspended or community sentence, or when they are released into the community on licence after serving a determinate, extended or life sentence. This article aims to promote awareness of joint working between probation and mental health services and the role of approved premises. It also describes a successful example of such joint working at Elliott House, approved premises for mentally disordered offenders in Birmingham, UK.
\end{abstract}

\section{LEARNING OBJECTIVES}

- Develop an understanding of the role of probation and key responsibilities of probation officers and approved premises

- Be aware of current changes within probation services

- Gain an understanding of joint working between probation services and psychiatrists

\section{DECLARATION OF INTEREST}

None

\section{The role of probation services in the criminal justice system}

In England and Wales, probation services are a part of the criminal justice system that works alongside the courts and police services in the management of offenders. Since their origins in the British temperance movement in the 1800 s, probation services have worked with offenders with the aim of reducing offending and improving the functioning of offenders. The Probation Service became a statutory body in 1907 as a result of the Probation of Offenders Act 1907 (McCarva 2008). Since that time, it has been subject to many reforms and has been influenced by changing political and societal views on criminality. It is currently facing perhaps one of the most radical changes in its history as a result of government plans outlined in the White Paper Transforming Rehabilitation: A Strategy for Reform (Ministry of Justice 2013a).

\section{The Transforming Rehabilitation agenda}

The major change resulting from the Transforming Rehabilitation agenda is a restructuring that resulted in thereplacement of the 35 probation trusts with 21 'community rehabilitation companies' (CRCs), supported by a smaller National Probation Service (NPS). The community rehabilitation companies will be responsible for managing lowand medium-risk offenders, and the NPS will be responsible for assisting courts in sentencing, managing high-risk offenders, approved premises and victim liaison units (Ministry of Justice 2013a). These organisational and structural changes have enabled private and third-sector (voluntary or charitable) organisations to tender for services carried by community rehabilitation companies and introduces the concept of payment by results to the field of rehabilitation of offenders (Home Office 2013). At a national level, the Ministry of Justice has contracted the work being undertaken by the 21 community rehabilitation companies to a number of private companies and newly formed partnership organisations from April 2015. The new owner organisations include Sodexo Justice Services in partnership with Nacro, the Achieving Real Change in Communities Community Interest Company, Purple Futures, the Reducing Reoffending Partnership, Working Links, EOS Works Ltd, MTCNovo and Seetec (Clinks 2014).

There has been much debate about the impact of these changes in regard to the fragmentation of services, the potential for duplication and increasing complexity (Garside 2014). Equally, some commentators have highlighted the benefits of an effective widening of the rehabilitation remit, with community rehabilitation companies offering all offenders 'through-the-gate' support, even those who would previously not have received input from probation services (Clougherty 2014). Through-the-gate support begins during offenders' final weeks in prison and continues through their release and resettlement in the community.
Rebekah Bourne is a consultant forensic psychiatrist with Birmingham and Solihull Mental Health NHS Foundation Trust and visiting forensic psychiatrist to Elliott House, Birmingham, UK. Rachna Rajput is a specialist registrar (ST5) with Birmingham and Solihull Mental Health NHS Foundation Trust and visiting specialist registrar to Elliott House. Richard Field is an acting senior probation officer with the National Probation Service and Deputy Approved Premises Manager at Elliott House.

Correspondence Dr Rebekah Bourne, Reaside Clinic, Reaside Drive, Birmingham Great Park, Rubery, Birmingham B45 9BE, UK. Email: rebekah.bourne@bsmhft. nhs.uk 
BOX 1 Responsibilities of the National Probation Service under the Transforming Rehabilitation agenda

- Preparing pre-sentence reports (PSRs) for courts, to help them select the most appropriate sentence

- Managing approved premises for offenders with a residence requirement on their sentence

- Assessing offenders in prison to prepare them for release on licence to the community, when they will come under National Probation Service supervision

- Helping all offenders serving sentences in the community to meet the requirements ordered by the courts

- Communicating with and prioritising the well-being of victims of serious sexual and violent offences, when the offender has received a prison sentence of 12 months or more, or is detained as a psychiatric patient

(Ministry of Justice 2013a)

Organisations responsible for the delivery of probation services will need to work collaboratively with mental health services to provide appropriate support for individuals with related needs. In view of extensive organisational changes, the interface between companies providing probation services and mental health services may differ significantly from previous working practices.

A number of services (Box 1) have been exclusively 'reserved' for the NPS, including the management of high-risk offenders. Its caseload will comprise around 30000 offenders a year (NPS 2014), supporting their rehabilitation while protecting the public.

\section{Probation services and probation officers}

For the purpose of this article, we will use the term 'probation services' to refer to services provided by both the NPS and community rehabilitation companies. Probation services work alongside and in partnership with a vast number of statutory and non-statutory agencies, including those in other areas of criminal justice, health, social care and third-sector organisations.

Probation services are also one of the 'responsible authorities' within the multi-agency public protection arrangements (MAPPA), along with the police and prison services. These organisations have a statutory duty to identify, manage and monitor high-risk offenders in the community. For more detail about MAPPA see Taylor \& Yakeley (2013).

Probation officers are sometimes referred to as 'offender managers' when working with other criminal justice organisations, although they are referred to as 'probation officers' by offenders. The key areas of responsibility of probation officers are outlined in Box 2.

\section{Community criminal justice supervision}

There are several ways in which offenders come into contact with probation services following conviction. It is important that psychiatrists have some understanding of these criminal justice sanctions, as only a small proportion of mentally disordered offenders will receive disposals under the Mental Health Act 1983 on conviction: many more will receive custodial or community sentences and have contact with probation services. Many different types of disposal options are open to the courts when they are sentencing convicted offenders (Box 3).

The type of sentence will depend on the seriousness of the offence and any aggravating or mitigating factors. These may include, for example, the offender's culpability, the level of harm to the victim, antecedent history and personal circumstances. There may also be a reduction in the sentence if the offender has entered a guilty plea at an early stage (Sentencing Council for England and Wales 2012). In many cases, the presentence report (PSR) prepared by the NPS will be considered in helping the sentencing court to decide whether to impose a custodial sentence or a community sentence and which requirements are suitable for the offender. In some circumstances

BOX 2 Roles and responsibilities of probation officers when working with offenders

- Providing advice and information about offenders to assist the court with sentencing

-Writing/presenting pre-sentence and pre-release reports

- Undertaking one-to-one and group activities to address offending behaviour, to reduce risk (e.g. in domestic violence, sexual offending) and to promote victim awareness

- Organising and overseeing offenders' unpaid work

- Supporting the rehabilitation and resettlement of offenders in the community

- Visiting offenders at home, in court, prison, approved premises and other penal institutions

- Supporting the victims of some violent and sexual crimes

- Liaising with the police, Social Services, health, voluntary and charity organisations to ensure that risk is managed appropriately at all times 
BOX 3 Disposal options after conviction

- Discharge

- Fine

- Community sentence

- Suspended sentence

- Custodial sentence:

- determinate prison sentence

- extended sentence

- life sentence

- Disposal under Part III of the Mental Health Act 1983

- Ancillary orders

(Sentencing Council for England and Wales 2012)

a psychiatric or psychological report will also be required to assist in sentencing.

Probation services will be involved in the supervision and management of offenders who receive a suspended sentence or a community sentence, or who are released into the community on licence (or parole) after serving a determinate, extended or life sentence in custody.

\section{Suspended sentences}

When a court imposes a custodial sentence of between 14 days and 2 years (or 6 months in a magistrates' court), the court may choose to suspend the sentence for up to 2 years (Sentencing Council for England and Wales 2012). This means that the offender does not go to prison immediately, but is given the opportunity to refrain from further offending and comply with specific requirements imposed by the court. These are the same requirements that are available to the court through community orders under the Criminal Justice Act 2003 (not to be confused with community treatment orders under the Mental Health Act).

If the offender does not comply with the requirements imposed or is convicted of a further offence during the operational period of the suspended sentence, the courts are able to activate in part or in full the suspended sentence from the original offence and may also impose a new sentence for the further offence.

\section{Community orders}

The sentence served by an offender in the community is called a community order. Section 117 of the Criminal Justice Act 2003 provides magistrates and judges with the options of 12 requirements when making a community order (Box 4).
The Criminal Justice Act requires that, when deciding which requirements to include, the court must be satisfied on three matters: that the restriction on liberty is commensurate with the seriousness of the offence(s), that the requirements are the most suitable for the offender and that, where two or more requirements are included, they are compatible with each other. The Sentencing Guidelines Council (2004: p. 6) states that:

\begin{abstract}
'In community sentences the guiding principles are proportionality and suitability. Once a court has decided that the offence has crossed the community sentence threshold and that a community sentence is justified, the initial factors defining which requirements to include in a community sentence should be the seriousness of the offence committed.'
\end{abstract}

\section{Licence}

All offenders subject to determinate sentences of 12 months or more are required to serve the second half of their sentence in the community on licence. Offenders serving determinate sentences are released from custody half way through their sentence and will be subject to specific requirements until their sentence expires. Individuals convicted of a 'specified offence' listed in schedule 15 of the Criminal Justice Act 2003 may receive an extended period on licence after release, to protect the public. When an offender is convicted of a 'serious' specified offence and receives an indeterminate sentence, a minimum term (tariff) will be set, at the end of which the person convicted will be eligible to apply for release on parole. The Parole Board should direct release only if it is satisfied that the offender no longer presents a significant risk of harm to the public.

B0X 4 Requirements available to the courts when making a community sentence

- Unpaid work

- Specified activity

- Programme to change offending behaviour

- Prohibited activity

- Curfew

- Exclusion

- Residence

- Mental health treatment requirement (MHTR)

- Drug rehabilitation requirement (DRR)

- Alcohol treatment requirement (ATR)

- Supervision

- Attendance centre (for offenders aged 25 years or below)

(Sentencing Guidelines Council 2004) 
Individuals subject to indeterminate sentences will be subject to licence for the rest of their life (Ministry of Justice 2009), although the Secretary of State has the power to suspend contact with the NPS if they feel it is appropriate to do so.

While on licence, an offender will be subject to supervision and other specific requirements to protect the public and support rehabilitation and resettlement into the community. If an offender serving a determinate sentence breaches their conditions, they may be sent back to prison and required to serve the remainder of their sentence there (Sentencing Council for England and Wales 2012). All licences must include 'the standard conditions', for example, a requirement that the offender be of good behaviour. Probation services are responsible for supervising all individuals aged 18 years or over on licence.

\section{Breaches}

Decisions regarding enforcement of community sentences and licences are statutory responsibilities of probation services and must be based on breaches of specific requirements or evidence of increased risk that is no longer manageable in the community. The processes for enforcement differ depending on the type of sentence being served by the offender and level of risk of serious harm presented. Breaches of community sentences are dealt with by a return to court, and breaches of licence requirements result in the offender being returned to custody. If there is evidence that the risk of serious harm presented by an individual has increased, enforcement proceedings can be expedited to protect the public or specific persons identified as being at risk (Ministry of Justice 2013b).

\section{Mental health treatment requirements}

In 2009, the Department of Health published an independent review by Lord Bradley into the support offered to people with mental health problems and intellectual disability (referred to as learning disabilities) in the criminal justice system. The report highlighted the growing number of individuals with mental health problems in custody, and the need for better options in relation to diversion of mentally disordered offenders from custody (Department of Health 2009).

There are several options available in relation to diversion. Mental health treatment requirements (MHTRs) were introduced in 2005, along with drug rehabilitation requirements (DRRs) and alcohol treatment requirements (ATRs). The main purpose of MHTRs was to ensure that offenders are able to access appropriate treatment in the community (Scott 2012). The MHTR is appropriate for offenders who meet three criteria: they require treatment for mental health-related needs; there are concerns regarding future engagement; and the court is of the view that it is not appropriate to divert them from the criminal justice system altogether. An MHTR allows an individual still serving a community sentence to engage with a treatment programme. This is a form of diversion within rather than away from the criminal justice system (Scott 2012).

The number of community orders with an MHTR remains low. When they were first available in 2006, there were 725 MHTRs issued as part of a community order. In 2013, just 613 such orders were made, with only $0.04 \%$ of community orders containing an MHTR. This compares with around $5 \%$ of orders containing a requirement for drug treatment (DTRs) and around 3\% for alcohol treatment (ATRs) during the same period (Ministry of Justice 2014). The government's Green Paper on effective punishment and rehabilitation of offenders commented that the level of use of MHTRs was disappointing (Ministry of Justice 2010).

Five years on from the Bradley Report, the Centre for Mental Health conducted an independent review of progress made (Durcan 2014). This review found that, although progress in some aspects had been made, there was still a need for further development of diversion services. In many regions there were still challenges faced in the use of MHTRs. The main hurdle to more widespread use was felt to be 'the willingness of mainstream care and support providers to engage with criminal justice agencies and to see these and the people who have contact with them as part of the community they serve' (Durcan 2014: p. 21).

\section{Criteria for MHTRs}

The criteria for an MHTR as part of either a suspended sentence order or a community order are shown in Box 5.

BOX 5 Conditions for a mental health treatment requirement (MHTR)

- The offender's mental condition requires and is susceptible to treatment but does not warrant making a hospital order or guardianship order under the Mental Health Act 1983

- Arrangements have been or can be made for treatment

- The offender expresses willingness to comply with the MHTR

(Scott 2012) 
For an MHTR to be made, there must be a named registered medical practitioner or registered psychologist supervising the treatment. An MHTR requires offenders to engage in specific treatment, the nature of which will depend on their condition, for a specified period of time. An MHTR is not often made alone: it is usually combined with a supervision requirement for the offender to engage with a probation officer. This officer will address other matters in relation to offending and monitor compliance with the order (Scott 2012).

\section{Consequences of breaching an MHTR}

If the requirements of a community order are breached, the individual can be taken back to court and more onerous requirements added, or a custodial sentence can be imposed. However, concerns have been expressed by court professionals about the impact of such breaches on offenders' mental health. Probation staff, on the contrary, generally see breach proceedings as a way of encouraging compliance, particularly for those who are high risk (Scott 2012).

\section{Barriers to the use of MHTRs}

The Centre for Mental Health, in collaboration with the Criminal Justice Alliance, has published policy briefings on overcoming the barriers to the use of the MHTR. The most recent of these (Scott 2012) fully explores these barriers.

There tends to be uncertainty regarding which offenders will benefit from MHTRs and there is little published evidence on this subject. Often an offender has many complex problems and there can be differing views among professionals regarding who should receive an MHTR, with some arguing that mental health problems should not be dealt with via the criminal justice system. There is also a lack of awareness among professionals about community sentences and MHTRs, and this can be compounded by uncertainty regarding the process and practice of such orders and the joint working with probation services that is required (Scott 2012).

One study (Mair 2009) found that magistrates and judges were equally uncomfortable with the use of MHTRs: they felt that their knowledge about them was sparse and their knowledge of local mental health services was insufficient.

There can be uncertainty regarding when an offender has breached an MHTR and how this should be managed. Healthcare professionals may be concerned about damaging their therapeutic relationship with the patient, but probation officers rely on health professionals to report non-compliance. There can be problems with communication between the two agencies and differing expectations of each other.

Khanom et al (2009) conducted qualitative research into the use of the MHTR, interviewing 56 professionals from the courts, probation and health services about their understanding of MHTRs and how they worked in practice. They found that one of the biggest barriers to the use of MHTRs was the need for formal psychiatric reports. Obtaining these reports can be a lengthy process and requires additional funding through legal aid. Often, the psychiatrists writing the reports are independent, have no prior knowledge of the individual and will not be the ones responsible for the supervision of any subsequent MHTR.

\section{The role of approved premises}

Approved premises were previously known as probation hostels or bail hostels. They provide residential placements for offenders on bail awaiting sentence and for those serving a community sentence or released on licence following a term of imprisonment. They offer a structured environment for offenders where enhanced supervision is available as well as support in engaging in rehabilitative activities such as education, training and employment (National Offender Management Service 2014a).

Approved premises have been identified as an important part of the criminal justice system. Over the past 10-15 years, their focus has shifted towards the accommodation of more high-risk offenders, which has made them an important public protection measure. Offenders will be placed in approved premises if their risk of serious harm is 'medium' or above and it is considered inappropriate to manage them in a less restrictive environment (National Offender Management Service 2014b). Since the recent organisational changes in probation services, the management of approved premises has become the responsibility of the newly formed NPS (National Offender Management Service 2014c).

There are 101 approved premises in England and Wales. All regions have at least one, but more populated areas have several. They have approximately 2200 beds, only 112 of which are for women. Owing to this limited capacity, there is often pressure on beds, especially for women (National Offender Management Service 2014b). Although approved premises are a form of supervised accommodation, they are not permanent placements. After about 6 months, with the support and approval of their probation officer, offenders will move on to other forms of supported or independent accommodation. 
Most approved premises are for male offenders and they prioritise individuals assessed as posing 'high' or 'very high' risk of serious harm. A much smaller number specialise in accommodating female offenders and offenders with addictive behaviour and mental health problems. More recently, there has been development of specialist approved premises for offenders whose management is complex because of personalityrelated difficulties. This is part of the Department of Health and National Offender Management Service strategy for the management of offenders with personality disorders (Craissati 2011). These units are referred to as psychologically informed planned environments (PIPEs), and staff have additional training in understanding and working with offenders with personality disorder (Turley 2013).

\section{Elliott House: approved premises for mentally disordered offenders}

Elliott House is a specialist approved premises in Birmingham offering accommodation for male offenders aged 18 years or above who have diagnosed or suspected mental health problems. They must be charged with or convicted of a criminal offence and meet the other criteria for admission to standard approved premises, but require specialist mental health interventions. Most residents will have an established diagnosis of mental illness or autism spectrum disorder. Offenders with a personality disorder or substance use disorder are considered as long as they have a comorbid mental illness. Elliott House was opened in 1993 and was born out of a partnership between West Midlands Probation Service and the regional forensic mental health service based at Reaside Clinic, Birmingham (Geelan 2000). It is currently run by the NPS with specialist input from the forensic services of Birmingham and Solihull Mental Health NHS Foundation Trust. We work as part of the team at Elliott House.

Although Elliott House functions much like other approved premises and is managed by probation staff, the mental health multidisciplinary team is well integrated within the service. It provides sessional input by a consultant forensic psychiatrist, community psychiatric nurse, psychologist and occupational therapist. There is a strong focus on joint working between mental health and probation staff and the team meets weekly to review the progress of residents and formulate management plans.

On arrival at Elliott House, all residents sign an agreement that information can be shared between its probation and mental health staff. The mental health team offers support to all residents, even those who are already engaged with a mental health team, although they do not hold care programme approach (CPA) responsibility. The team focuses on working in a collaborative manner with external mental health teams, drug and alcohol services and probation officers involved with residents' care. For some residents, placement at Elliott House is their first experience of contact with community mental health services, their diagnosis having been made in prison. In these cases, it is ensured that appropriate followup is arranged once they move on to their next accommodation.

The services offered at Elliott House have developed over time. It is a national resource, accommodating offenders from around the country, although priority is given to referrals from the West Midlands area. There are one or two similar services around England and Wales, but Elliott House is unique in that it offers multidisciplinary forensic mental healthcare to all residents. One of the greatest challenges that we face as a service is the availability of suitable supported move-on accommodation and obtaining funding for this. Further challenges are faced in ensuring that residents continue to engage with mental health services after they have moved on. These are similar to the problems related to continuity of care that are encountered on release from prison (Jarrett 2012).

\section{Good practice when working with probation services}

Effective joint working between mental health and probation services can be an effective route towards supporting recovery for mentally disordered offenders, a group who can be challenging for services to work with. The first step in joint working is to have an awareness of the involvement of probation services: an offender's forensic history should focus not only on convictions and periods in custody, but also past and current probation involvement.

Concerns about sharing information and breaching confidentiality can be a barrier to joint working. Gaining the offender's signed consent to share information with probation services is possible in most cases. If this is not forthcoming, then clinicians should refer to professional guidelines such as those published by the Royal College of Psychiatrists (2010). It is always important to consider the central tenets of balancing necessity, proportionality and risk when joint working (with or without consent). Also, making contact with probation services is often 
beneficial in terms of gathering information in complex and high-risk cases. It may be necessary to utilise the MAPPA framework for this purpose (Taylor 2013).

It is important for psychiatrists to remaininvolved in the care of patients who come into contact with the criminal justice system. Psychiatrists should be familiar with MHTRs as a disposal option and be willing to recommend them to the courts. As the vast majority of mentally disordered offenders are in contact with secondary care, it will most often be general adult psychiatrists who will be involved with their use. Although full detailed psychiatric reports are appropriate and requested in some cases, for patients who are well known to clinicians and have an established treatment plan, a simple letter or short report to the court would be an appropriate way of recommending an MHTR. The involvement of treating psychiatrists in this way allows courts and probation services to be advised by professionals who know the patients and will be continuing to treat them in the future. It also saves time and public funds.

\section{Conclusions}

Joint working with probation services is a crucial part of a psychiatrist's work with mentally disordered offenders in the community. As probation services face the same challenges of restructuring that are currently besetting the health service, there is a risk that this will become ever more challenging. Appropriate sharing of information and collaboration can be effective ways of engaging and supporting even the most challenging and chaotic of patients.

\section{References}

Clinks (2014) The Transforming Rehabilitation Programme: The New Owners of the Community Rehabilitation Companies. Clinks (www. clinks.org/sites/default/files/table-of-new-owners-of-crcs.pdf).

Clougherty T (2014) Lost in probation? The House Magazine, 7 Feb: 25-6. (http://www.crimeandjustice.org.uk/sites/crimeandjustice.org. uk/files/Policy\%20Review\%20\%E2\%80\%93\%20Probation.pdf).

Craissati J, Minoudis P, Shaw J, et al (2011) Working with Personality Disordered Offenders: A Practitioners Guide. National Offender Management Service.

Department of Health (2009) The Bradley Report: Lord Bradley's Review of People with Mental Health Problems or Learning Disabilities in the Criminal Justice System. Department of Health.

Durcan G, Saunders A, Gadsby B, et al (2014) The Bradley Report Five Years On: An Independent Review of Progress to Date and Priorities for Further Development. Centre for Mental Health.

Garside R (2014) Lost in probation? The House Magazine, 7 Feb: 27. (http://www.crimeandjustice.org.uk/sites/crimeandjustice.org.uk/ files/Policy\%20Review\%20\%E2\%80\%93\%20Probation.pdf).

Geelan S, Griffin N, Briscoe J, et al (2000) A bail and probation hostel for mentally disordered defendants. Journal of Forensic Psychiatry, 11: 93-104.
Home Office, Ministry of Justice (2013) Reducing Reoffending and Improving Rehabilitation. GOV.UK (https://www.gov.uk/government/ policies/reducing-reoffending-and-improving-rehabilitation). Accessed 23 Mar 2015.

Jarrett M, Thornicroft G, Forester A, et al (2012) Continuity of care for recently released prisoners with mental illness: a pilot randomized controlled trial testing the feasibility of Critical Time Intervention. Epidemiology and Psychiatric Sciences, 21: 187-93.

Khanom H, Samele C, Rutherford M (2009) A Missed Opportunity? Community Sentences and the Mental Health Treatment Requirement. Sainsbury Centre for Mental Health.

Mair G, Mills H (2009) The Community Order and the Suspended Sentence Order Three Years On: The Views and Experiences of Probation Officers and Offenders. Centre for Crime and Justice Studies.

McCarva R (2008) England and Wales. In Probation in Europe (eds AM van Kalmthout, I Durnescu): 255-94. Aolf Legal Publishers.

Ministry of Justice (2009) Life sentence and imprisonment for public protection. In Prison Service Order 4700 Indeterminate Sentence Manual. Ministry of Justice (https://www.justice.gov.uk/offenders/ psos/pso-4700-indeterminate-sentence-manual).

Ministry of Justice (2010) Breaking the Cycle: Effective Punishment, Rehabilitation and Sentencing of Offenders (Cm 7972). Ministry of Justice.

Ministry of Justice (2013a) Transforming Rehabilitation: A Strategy for Reform. Response to Consultation CP(R)16/2013. Ministry of Justice (https://consult.justice.gov.uk/digital-communications/transformingrehabilitation/results/transforming-rehabilitation-response.pdf).

Ministry of Justice (2013b) Recall, Review \& Re-Release of Recall Offenders (Prison Service Instruction 30/2014). Ministry of Justice (https://www.justice.gov.uk/downloads/offenders/psipso/psi-2014/ psi-30-2014-recall-review-of-offenders.pdf).

Ministry of Justice (2014) Offender Management Statistics Bulletin. England and Wales: Quarterly - October to December 2013. Annual January to December 2013. Ministry of Justice.

National Offender Management Service (2014a) Approved Premises Manual (PI 32/2014). National Offender Management Service (http:// www.justice.gov.uk/downloads/offenders/probation-instructions/pi32-2014-approved-premises.doc)

National Offender Management Service (2014b) Approved Premises Instruction (PI 32/2014). National Offender Management Service.

National Offender Management Service (2014c) National Offender Management Service: Business Plan 2014-2015. National Offender Management Service.

National Probation Service (2014) About us. National Probation Service (https://www.gov.uk/government/organisations/nationalprobation-service/about). Accessed 18 Mar 2015

Royal College of Psychiatrists (2010) Good Psychiatric Practice: Confidentiality and Information Sharing (2nd edn) (College Report CR160). Royal College of Psychiatrists.

Scott G, Moffatt S (2012) The Mental Health Treatment Requirement: Realising a Better Future. Centre for Mental Health.

Sentencing Council for England and Wales (2012) Types of sentence. Sentencing Council (http://www.sentencingcouncil.org.uk/aboutsentencing/types-of-sentence). Accessed 18 Mar 2015.

Sentencing Guidelines Council (2004) New Sentences: Criminal Justice Act 2003. Guideline. Sentencing Council (http://www. sentencingcouncil.judiciary.gov.uk/docs/web_new_sentences_ guideline1.pdf)

Taylor R, Yakeley J (2013) Working with MAPPA: Guidance for Psychiatrists in England and Wales (Faculty Report FR/FP/01). Royal College of Psychiatrists.

Turley C, Payne C, Webster S (2013) Enabling Features of Psychologically Informed Planned Environments. National Offender Management Service.

\section{MCQ answers}

1 b $\quad 2$ e $\quad 3$ b $\quad 4$ a $\quad 5$ a 


\section{MCOs}

Select the single best option for each question stem

1 When making offenders subject to suspended sentences or community orders,

requirements available to courts include:

a hospital order

b curfew

c fine

$\mathrm{d}$ inclusion zones

e paid work.

2 The mental health treatment requirement:

a does not need a named medical practitioner or psychologist

b requires a patient to take medication

$c$ is commonly used d requires a patient to be detainable under the Mental Health Act

e requires joint working between probation and mental health services.

3 As regards approved premises:

a they are available only for offenders leaving custody

b they offer a structured environment for offenders where enhanced supervision is available

c only offenders will be placed in approved premises if their risk of harm is low

d there are 201 approved premises in England and Wales

e the management of such premises is the responsibility of the mental health services.
4 Types of sentence available to courts on conviction of a criminal offence include:

a suspended sentence

b mental health treatment requirement

c drug treatment requirement

$\mathrm{d}$ alcohol treatment requirement

e unpaid work.

5 A responsibility of the National Probation Service under the Transforming

Rehabilitation agenda is:

a preparing pre-sentence reports

b granting parole

c referring to appropriate mental health teams

d supervising all offenders in the community

e supervising offenders under the age of 18 . 